\title{
O LUGAR DA FORMAÇÃO E MEDIAÇÃO NAS LITERACIAS E COMPETÊNCIAS MIDIÁTICAS DE CRIANÇAS E JOVENS ESTUDANTES ${ }^{1}$
}

\author{
THE ROLE OF EDUCATION AND MEDIATION IN MEDIA LITERACIES AND COMPETENCIES OF YOUNG \\ STUDENTS
}

\section{EL LUGAR DE LA FORMACIÓN Y MEDIACIÓN EN LOS ALFABETISMOS Y COMPETENCIAS MEDIÁTICAS DE NIÑOS Y JÓVENES ESTUDIANTES}

Monica Fantin ${ }^{2}$

\begin{abstract}
Resumo: $O$ texto discute o lugar que a formação e as mediações entre pares, escolares e familiares ocupam nas aprendizagens "digitais" e nas competências midiáticas de crianças e jovens estudantes, a partir de uma pesquisa interinstitucional desenvolvida em 6 universidades brasileiras, no contexto de uma rede internacional de pesquisadores que investiga a temática das competências midiáticas para a cidadania. A pesquisa mais ampla, de abordagem quali-quantitativa, envolveu diferentes dimensões das competências midiáticas entre crianças, jovens, estudantes universitários, professores e comunicadores, e o recorte do artigo enfatiza o papel da formação na construção das competências midiáticas de estudantes de 9 a 12 anos e 14 e 16 anos em diferentes contextos socioculturais. O texto situa alguns fundamentos sobre formação, aprendizagem, mediação e competências midiáticas bem como os aspectos metodológicos da pesquisa. $\mathrm{Na}$ discussão sobre a formação recebida ou não pelos estudantes, o artigo destaca o lugar da aprendizagem autodidata, da aprendizagem com amigos, da mediação escolar e familiar e da formação em workshops. Por fim, situa alguns desafios da formação entendida como mediação educativa na promoção de experiências midiáticas e culturais responsáveis do ponto de vista semiótico, expressivo/estético e ético na escola e fora dela.
\end{abstract}

Palavras-chave: Formação. Mediação. Competências midiáticas. Estudantes. Cultura digital.

Abstract: This article discusses the place that education and mediations among peers, schools and families have in "digital" learnings and media competencies of students aged 9 to 12 and 14 to 16 based on an interinstitutional study conducted at 6 Brazilian universities. The work was conducted in association with an international network of researchers who investigate the theme of media competencies for citizenship. The broader study, which had a qualitative and quantitative approach, involved different dimensions of media competencies among children, youth, university students, teachers and communicators, this article

\footnotetext{
${ }^{1}$ Essa reflexão resulta de uma pesquisa financiada pelo Conselho Nacional de Pesquisa, CNPq e pela Fundação de Amparo à Pesquisa do Estado de Minas Gerais, FAPEMIG.

${ }^{2}$ Universidade Federal de Santa Catarina. Florianópolis, Santa Catarina, Brasil.
} 
emphasizes the role of education in different sociocultural contexts in the construction of media competencies among young students. The article locates some foundations of education including, learning, mediation, media literacies and the methodological aspects. In the discussion about some aspects of education received or not by the students, the article reveals the place of self-learning, of learning with friends, of school and family mediation, and of education in workshops. Finally, it highlights some challenges for education understood as educational mediation for the promotion of mediatic and cultural experiences responsible from a semiotic, expressive/aesthetic and ethical perspective in and outside schools.

Keywords: Education. Mediation. Media competencies. Students. Digital culture.

Resumen: El texto discute el lugar que ocupan la formación y las mediaciones entre pares, escolares y familiares en los aprendizajes "digitales" y en las competencias mediáticas de niños y jóvenes estudiantes, a partir de una investigación interinstitucional desarrollada en 6 universidades brasileñas, en el contexto de una red internacional de investigadores que pesquisa el tema de las competencias mediáticas para la ciudadanía. La investigación más amplia, con un enfoque cualitativo y cuantitativo, involucró diferentes dimensiones de las competencias mediáticas entre niños, jóvenes, estudiantes universitarios, docentes y comunicadores, y el recorte del artículo enfatiza el papel de la formación en las competencias mediáticas de estudiantes de 9 a 12 años y de 14 y 16 años en diferentes contextos socioculturales. El texto establece algunos fundamentos sobre la formación, el aprendizaje, la mediación y las competencias mediáticas, así como los aspectos metodológicos de la investigación. En la discusión sobre la formación recibida (o no) por los estudiantes, el artículo destaca el lugar del aprendizaje autodidacta, del aprendizaje con amigos, de la mediación escolar y familiar y de la formación en talleres. Finalmente, sitúa algunos retos de la formación entendida como mediación educativa en la promoción de experiencias mediáticas y culturales responsables desde un punto de vista semiótico, expresivo/estético y ético, en la escuela y fuera de ella.

Palabra clave: Formación. Mediación. Competencias mediáticas. Estudiantes. Cultura digital.

\section{APRENDIZAGEM, FORMAÇÃO E MEDIAÇÃO NA CULTURA DIGITAL: LITERACIAS E COMPETÊNCIAS MIDIÁTICAS EM QUESTÃO}

Entre tantos desafios colocados à educação na busca de uma aprendizagem significativa e dialógica, destacamos a importância de saber o que crianças e jovens fazem com as mídias e tecnologias móveis no contexto da cultura digital a fim de articular com as práticas pedagógicas. O que acessam, assistem, produzem e compartilham? Como se relacionam e se apropriam das tecnologias digitais? Que competências demonstram ter? Qual o papel da reflexão nessas práticas midiáticas? E ainda, como aprendem a usar os artefatos? Recebem algum tipo de formação na escola, aprendem com os pares, familiares ou aprendem sozinhos?

Quando se fala de aprendizagem na cultura digital, é muito comum se referir ao "autodidatismo digital", afinal o "autoensino" na era digital também tem sido uma forma de "autoaprendizagem", diz SeftonGreen (2019, p.127). Ao questionar os "supostos novos modos de aprendizagem", presumidos como intrínsecos à era digital, o autor situa os caminhos do autodidatismo e demonstra que eles não são tão novos 
assim. Embora diversas plataformas e aplicativos disponíveis na cultura digital propiciem uma diversidade de autoensino e autoaprendizagens com ou sem tutoriais sobre os mais diferentes temas, grande parte de tais práticas também solicitam certo treino, disciplina, interesse e motivação - aspectos que também se verificam em outras "pedagogias" ou experiências educacionais.

Ainda que plataformas de compartilhamento de vídeos como o Youtube, por exemplo, propiciem aprendizagens singulares, personalizadas, flexíveis, sob demandas e com uma variedade de recursos, métodos e técnicas multimodais, é uma plataforma comercial, mediada e controlada por diversos interesses, mas que também propicia diferentes tipos de relações pedagógicas. Ao comparar a autoaprendizagem com o Youtube e autoaprendizagem com as artes gráficas, por exemplo, Sefton-Green (2019) argumenta que ambas demonstram práticas autodidatas de tipos mais antigos e que antecedem a digitalização.

Certas práticas exclusivamente digitais e ligadas ao movimento maker também teriam suas raízes em práticas dos jogos, como parte da cultura remix e de outras formas de arte também baseadas em outras abordagens educacionais. A diferença é que em tais práticas, "a aprendizagem ocorre através de interações online em comunidades de pares conhecedores. Raramente existem autoridades credenciadas, embora os indivíduos frequentemente tenham grande influência, por meio de expertise" (SEFTON-GREEN, 2019, p.130). Nesses casos não haveria programas de estudos convencionais nem avaliação sobre as formas de participação nestes tipos de comunidade, pois seriam motivados pelo interesse e desejo de pertencimento. Aliado a isso, o autor enfatiza que a "forte sensação de estar fora das estruturas e sistemas educacionais formais reforça a sensação de autenticidade, integridade e poder desses tipos de experiências de autoaprendizagem dos participantes" (idem).

É nessa perspectiva que é possível situar a Teoria da Aprendizagem Conectada (ITO et al, 2010), ao propor um modelo de aprendizagem orientada por interesses em que o sujeito esteja motivado pela participação em grupos de afinidade (GEE, 2006) online, como forma de avançar em suas aprendizagens a partir da cultura participativa. Para Sefton-Green (2019, p.132), a aprendizagem conectada parte de uma noção de interesse ou motivação que envolve participação em projetos e intervenções que ocorrem sobretudo fora das instituições formais, mas "conectadas com domínios de conhecimento que permitem uma transferência de retorno ou formas de cruzamento entre os domínios do conhecimento formal e informal".

Essa ênfase no sentido de transferência e transposição mencionadas acima, é um dos indicadores de autodidaxia proposto por Belloni (2010) quando analisa as formas de apropriação das TICs pelas crianças mobilizadas na aprendizagem mediada por computadores. Para a autora, "é o ponto de vista da autodidaxia, que tenta identificar as formas espontâneas de lidar com as técnicas e a transposição de formas para outras aprendizagens"(BELLONI, 2010, p.223). Junto à autodidaxia, outra variável que ela menciona se é a 
colaboração e cooperação, correlacionados ao que a autora denomina de novos modos de aprendizagem, sem desconsiderar a importância das mediações da escola e do professor com intervenções sistemáticas e fundamentadas cientificamente, ao lado da família e dos grupos de pares no espaço escolar. Tais indicadores se revelam na ajuda mútua diante dos usos das tecnologias e nas interações construídas no trabalho colaborativo entre pares, que a autora articula com a "didaxia horizontal" (p.232) como um forte motivador que atua na consolidação de aprendizagens e caracterizam a transposição de operações cognitivas de uma situação a outra. E tal processo ocorreria tanto em relação aos conhecimentos escolares como às habilidades de operar os artefatos tecnológicos.

É interessante observar que embora o sentido de autoaprendizagem e autodidaxia esteja presente em outras práticas - como por exemplo da cultura maker, cada vez mais identificada com o DIY, Do It Yourself, "faça você mesmo" -, há diferenças entre autoensino, autoaprendizagem, autodidatismo e autoformação. E é importante situar tais entendimentos para esclarecer o ponto de vista adotado nesta reflexão.

Ainda que responsabilidade e autonomia individual na aprendizagem sejam requisitos importantes, “a autoformação é um construto típico da educação de adultos que na literatura abarca uma pluralidade de significados, onde instâncias teóricas se intercruzam com preocupações da natureza prática", diz Bochicchio (2014, p.49). Para o autor, a autoformação seria uma necessidade da pós-modernidade com o sentido da lifelong e lifewide learning, educação ao longo da vida, em que prevalece o projeto utópico de realizar um novo modelo de sociedade fundado no conhecimento, kwnowledge society. Nessa perspectiva enunciada por Bochicchio, autoformação envolve também os conceitos de aprendizagem de si e autoaprendizagem, aprendizagem autodirigida, autodeterminação e autogestão. Portanto não seria muito apropriado usarmos esse conceito para falar da autoaprendizagem de crianças.

Por sua vez, a complexidade do sentido de formação remete ao seu entendimento amplo e polissêmico, e frequentemente tem sido usado como sinônimo de educação e/ou instrução. Apesar de certa confusão entre oferta formativa e necessidade de atualização que reproduz modelos conhecidos diante da tensão entre mudança e inovação, segundo Qualigno (2014), a instrução, formação ou educação envolve a perspectiva de emancipação do saber, caso contrário, a formação se reduziria à "reprodutibilidade técnica" conduzindo ao falimento de si mesma, ressalta o autor.

Tal perspectiva emancipatória estaria presente no sentido de formação como Bildung. Dozol (2003) nos lembra que mesmo na obra de filósofos como Kant, Pestalozzi e Goethe, a palavra Bildung (formação) é traduzida por "educação", pois segundo alguns tradutores não haveria distinção precisa entre Bildung (formação) e Erziehung (educação). Há quem prefira usar Bildung como o sentido mais amplo da construção autônoma de si mesmo, e educação no sentido de pressupor a condução da aprendizagem por um agente externo ao indivíduo, diz a autora, que continua sua reflexão distinguindo formação - que envolve 
cooperação ativa e livre do sujeito envolvido - e educação, que envolve autoridade e obediência. Aos que diferenciam tais conceitos ligando o termo da formação ao processo pelo qual ao formar-se o indivíduo desenvolve física e moralmente, e educação faria referência à ação de criar, educar, adestrar/treinar, esclarece a autora. "Talvez uma das funções das distinções seja a de oferecer critérios que esclareçam ou delimitem as competências quanto à formação em sentido mais amplo e educação no âmbito institucional” (DOZOL, 2003, p.17). É nessa perspectiva que a autora identifica a "dimensão pedagógica da formação com o conceito de educação".

Embora tal concepção de formação revele um sentido mais amplo, no recorte desse artigo a formação também será entendida a partir da especificidade ligada aos âmbitos da educação formal e informal e suas fronteiras (FANTIN, 2018). Na diversidade de experiências que a formação propicia, consideramos também a experiência estética, o conhecimento sensível, o conhecimento corporal e suas transformações no âmbito da sensibilidade e cognição promovidas pelas tecnologias digitais, como destaca Diodato (2015). Nessa perspectiva, a formação envolve os saberes, os conhecimentos, as aprendizagens e as práticas midiáticas que articulam experiências nos mais diferentes espaços da educação formal e informal nas fronteiras da cultura digital.

Deste modo, consideramos que os sentidos dos conceitos acima - formação, educação, autoformação, autodidaxia e autoaprendizagem - articulam-se nas práticas pedagógicas, midiáticas e culturais e nas mediações promovidas pelas multiliteracias.

A perspectiva das novas e múltiplas literacias - construída nas complexas interfaces entre lingüística, antropologia, epistemologia - é fundamental para entender as relações entre as práticas sociais e suas negociações de sentidos e aprendizagens no contexto da convergência das mídias, tecnologias e linguagens. A ideia de multiliteracias redefine a articulação dos conceitos e dos campos de forma crítica expandindo-se em diversas formas de expressão visual, sonora, performática, eletrônica e digital. Assim, “os conhecimentos, as habilidades e as competências necessárias para a plena participação na sociedade contemporânea, e todas essas habilidades são vistas como fundamentalmente vinculadas às práticas intelectuais e sociais conhecidas como alfabetização" (COPE;KALANTZIS, 2000, p.18).

A reconceitualização do processo de alfabetização/letramento para além da visão instrumental amplia o entendimento das mídias e tecnologias como cultura, envolvendo também conceitos como media e digital literacy - que para Buckingham (2005, p.4) seria o conhecimento e as habilidades que os estudantes adquirem no processo ensino-aprendizagem sobre as mídias. Por sua vez, tal processo necessariamente envolve 'leitura' e 'escrita' de mídias no sentido da reflexão, compreensão crítica e participação ativa. Os múltiplos letramentos também abarcam o conceito informational literacy, e dizem respeito ao sentido de cidadania, participação e democracia, e envolvem o conhecimento sobre as formas de uso e funcionamento 
da internet e seus códigos; saber acessar, selecionar e certificar informações produzidas, consumidas, veiculadas na Internet e suas redes; a confiabilidade dos websites e as competências de uso para produção e compartilhamento de conteúdos digitais de forma responsável.

Nessa compreensão, o conceito de competência pode ser entendido a partir das multicompetências na cultura digital, como sugere Rivoltella $(2005$, p.4) ao destacar três linhas de ação: i) explicitar e problematizar as competências tácitas para se ter a consciência de determinados processos e "transformar o seu saber fazer num saber de saber fazer"; ii) desenvolver a capacidade de reflexão; e iii) possuir a competência das competências, pois a multiplicidade de competências favorece o desenvolvimento de metacompetências entendidas como a "capacidade de organizar as diferentes dimensões".

Tal entendimento pode dialogar com Ferrés e Piscitelli (2012, p. 76), para quem a competência é "uma combinação de conhecimentos, habilidades e atitudes que se consideram necessários para um determinado contexto".

No quadro mais amplo das oito competências-chaves, propostas pela UNESCO (2013) e União Europeia como condição de cidadania e pertencimento, podemos listar: 1. Comunicação na língua materna; 2. Comunicação em línguas estrangeiras; 3. Competência em matemática, ciências e tecnologia; 4. Competência digital; 5 . Aprender a aprender; 6 . Competências sociais e cívicas; 7. Sentido de iniciativa e espírito empreendedor; e 8. Consciência e expressão cultural. Aqui a especificidade das competências midiáticas relaciona-se às competências digitais.

A partir do percurso histórico de organismos internacionais em diferentes países da OCDE (UNESCO, 2013), a educação midiática na escola tem sido proposta como possibilidade de melhorar o acesso aos meios e tecnologias convertendo-se na promoção de uma "educação crítica, ativa e plural sobre as mídias" (GARCIA, PÉREZ E GOMEZ, 2014, p.16). E na definição da Comissão Europeia, a competência midiática envolve a capacidade de acessar aos meios de comunicação (televisão, cinema, rádio, meios impressos, internet e todas dispositivos e tecnologias digitais), compreender e avaliar criticamente os diferentes aspectos e conteúdos dos mesmos e à criação das comunicações em uma variedade de contextos, esclarece Aguaded (2012).

Diante da complexidade do fenômeno da comunicação e suas práticas nas relações humanas, Ferrés (2007, p.103) destaca seis dimensões da competência midiática: linguagem (sentido plural, multimodal e multimídia); tecnologia (ferramentas/funções); processos de produção e difusão (como, porque, para que e para quem produzir); ideologia e valores (reconhecimento de conteúdos veiculados às mensagens e estereótipos presentes); recepção e audiência (interação com as mensagens recebidas); estética (análise formal e temática com sentido estético e sua relação com outras manifestações). $\mathrm{O}$ autor complementa seu entendimento de competência midiática a partir de conhecimentos, habilidades e atitudes relacionados às 
seis dimensões, que podem ser analisadas a partir de indicadores sobre "como as pessoas recebem mensagens e interagem com elas (análise de campo) e como as pessoas produzem as mensagens (nível de expressão)" (FERRÉS;PISCITELLI, 2012, p. 79).

Em geral, a construção de competências envolve formação e mediação educativa e cultural, que pode ser analisada a partir de diferentes olhares.

O entendimento de formação como processo de mediação, inspira-se no conceito de Martin-Barbero (2003) ao enfatizar a necessidade de reconhecer o conjunto de mediações que estruturam a realidade técnica dos meios. Mas para além do entendimento de mediação como processo de recepção de mensagens, Ortiz (1999, p.73) esclarece que “(...) a rigor, a noção de mediação se aplica a universos diversos: indivíduos, movimentos sociais, grupos populares, produtores da indústria cultural, etc. ." Para ele, o que MartinBarbero denomina de "mediação" pode se aproximar do que denominamos muitas vezes de "relações sociais e culturais".

A ênfase de Silverstone (2005) na "mídia como um processo de mediação" considera que a mídia envolve produtores e consumidores em atividades contínuas, com significados que se constroem ou que tem suas fontes nos textos mediados, mas que dilatam a experiência. Segundo o autor, "mediação implica movimento de significado de um contexto para outro, de um discurso para outro, de um evento para outro. Implica a constante transformação de significados" (2005, p.33).

Por sua vez, o entendimento de Orozco (1997) sobre mediação televisiva pode ser ampliado para outros meios, pois sua referência à múltipla mediação parte de um processo complexo, multidirecional e multidimensional que envolve diversos momentos, cenários e negociações que transcendem as telas. Neste caso, a mediação se manifesta por ações e discursos, com as mais diversas fontes: cultura, política, economia, classe social, gênero, idade, etnia, meios, condições situacionais e contextuais, instituições e movimentos sociais. $O$ caráter múltiplo da mediação proposta pelo autor envolve 4 grupos: individual (do sujeito como individuo ou sujeito social membro de uma cultura); situacional (as interações que o sujeito constrói, os cenários, as negociações); institucional (instituições sociais que mediam a agencia do sujeito); e tecnológico (as características do meio ou artefato tecnológico). E é fundamental entender como tais grupos atuam na mediação educativa.

No entanto, além das dificuldades epistemológicas relacionadas às maneiras de compreender a mediação, existe a dificuldade ética, que solicita elaboração de juízos sobre o exercício de poder no processo de mediação, diz Silverstone (2005). Se a mediação também envolve o trabalho de instituições, grupos e tecnologias, para o autor "todos nós somos mediadores, e os significados que criamos, são eles próprios nômades" (2005, p.42). Segundo ele, é fundamental "compreender o processo de mediação, compreender como surgem os significados, onde e com que consequências. Precisamos ser capazes de identificar os 
momentos em que o processo parece falhar, em que é distorcido pela tecnologia ou de propósito (...)". O autor menciona também a importância de compreender a política da mediação, "sua vulnerabilidade ao exercício do poder; sua dependência do trabalho de instituições e de indivíduos; e seu próprio poder de persuadir(...)"(2005, p.43).

Enfim, se a mediação envolve o trabalho de instituições, grupos e tecnologias e se somos todos mediadores a noção de mediação se aplica a diversos universos: indivíduos, movimentos sociais, grupos populares, produtores da indústria cultural e outros. Ao mesmo tempo, a mediação envolve negociação, movimentos de significado de um contexto para outro, de um discurso para outro, de um evento para outro. E isso permite entender a mediação como uma constante transformação de significados que também faz parte do processo formativo.

$\mathrm{Na}$ especificidade das interações das crianças com os dispositivos da cultura digital, Livingstone (2017) chama atenção às diferentes possibilidades formativas diante dos artefatos tecnológicos da cultura digital a argumenta que a mediação pode ser restritiva ou capacitadora. A esse respeito, Tisseron (2016) destaca a importância da negociação entre adultos e crianças, e enfatiza que a relação de crianças com as telas não é apenas um problema familiar ou escolar, mas de toda a sociedade. E tal perspectiva vai ao encontro do sentido de formação como mediação.

\section{ASPECTOS METODOLÓGICOS}

A pesquisa interinstitucional sobre competências midiáticas em cenários brasileiros e euroamericanos (BORGES;SILVA, 2019; FANTIN;BORGES, 2019) foi desenvolvida em 6 universidades brasileiras, no contexto de uma rede internacional de pesquisadores, Red Interuniversitaria Euroamericana de Investigacion en Competencias Mediáticas para la Ciudadanía - ALFAMED, composta por 13 países latinoamericanos e europeus que investiga a temática das competências midiáticas para a cidadania, e foi realizada entre 2014/2017.

Com abordagem mista ou quali-quantitativa (CRESWELL, 2010), a pesquisa envolveu estudantes do ensino fundamental, ensino médio e ensino superior, professores de cursos de licenciatura e profissionais da comunicação. No recorte desse artigo, a pesquisa diz respeito a 1001 estudantes - 502 entre 9 e 12 anos e 499 entre 14 e 16 anos do ensino fundamental e médio de seis cidades brasileiras: Brasília (DF), Florianópolis (SC), Juiz de Fora (MG), Ponta Grossa (PR), São Roque (SP) e Sorocaba (SP). A pesquisa empírica envolveu a aplicação de um questionário, hospedado no Google Forms, composto por 27 perguntas abertas e de múltipla escolha, com o objetivo de elaborar um perfil dos jovens estudantes e avaliar o desenvolvimento e nível de 
competência midiática. Após a aplicação do questionário nas escolas, de forma presencial e com o acompanhamento da equipe, as respostas obtidas foram organizadas em um arquivo do Excel (formato CSV,Comma-Separated Values), e posteriormente os dados foram sistematizados na base de dados utilizando o software estatístico R (https://www.r-project.org/), de livre distribuição e código aberto para a elaboração dos primeiros resultados. Na sequência foram utilizados o software SPSS versão 22 e teste quiquadrado para um refinamento dos dados de modo a possibilitar uma leitura dos níveis de competência bem como o cruzamento desses níveis a partir de diferentes variáveis de perfil dos participantes da pesquisa (BORGES;SILVA, 2019).

O questionário foi dividido em duas etapas: inicialmente o estudante respondia nove perguntas relacionadas ao seu perfil (sexo, idade, cidade, escola, etc.) e num segundo momento, questões relacionadas às seis dimensões da competência midiática sugeridas por Ferrés e Piscitelli (2012): linguagem, tecnologia, processos de interação, processos de produção e difusão, ideologia e valores e estética, que abarcou três perguntas, totalizando 18 questões.

Embora no recorte deste texto não haja um cruzamento dos dados obtidos nos diferentes contextos socioculturais e suas especificidades, destacamos a importância que tal aspecto possui no aprofundamento das análises e transversalidades. Aliás, os detalhes sobre as seis dimensões das competências midiáticas nas diferentes faixas etárias e suas diversas variáveis podem ser analisado na pesquisa mais ampla do referido estudo.

\section{RESULTADOS E ANÁLISES: A FORMAÇÃO NA CONSTRUÇÃO DAS COMPETÊNCIAS AUDIOVISUAIS}

Para discutir os resultados e as análises que emergiram da pesquisa, apresentaremos um breve perfil dos participantes da pesquisa - estudantes de 9 e 12 anos e 14 e 16 anos. Em seguida situaremos alguns dados tecendo considerações a respeito.

No perfil das crianças participantes da pesquisa entre 9 e 12 anos, 55, 52\% são do gênero masculino e $44,48 \%$ feminino, provenientes dos estados de SC (24,55\%), MG $(20,76 \%)$, PR $(20,16 \%)$, SP $(10,38 \%)$ e DF (24,15\%). As escolas que participaram da pesquisa eram públicas, privadas, e privadas com auxílio público, localizadas em contextos rural, urbano, centro e periferias. O perfil familiar e financeiros das crianças envolvia como familiares pequenos proprietários rurais, prestadores de serviços, profissionais liberais, operários, comerciários, funcionários públicos, empresários (SILVA; CARNEIRO; MEYER, 2019, p.38).

Para analisar os dados sobre a formação recebida no contexto do mapeamento das competências midiáticas, selecionamos as perguntas a respeito da formação recebida (ou não) em comunicação audiovisual 
e digital. As respostas foram as seguintes: Nunca tive formação (27,74\%); Aprendi sozinho (28,94\%); Aprendi na escola (15,57\%); Aprendi com a minha família (20,56\%); Aprendi com os meus amigos (7,79\%) e Aprendi em atividades extraescolares (1,40\%), como podemos ver no gráfico a seguir:

Gráfico 1 - Formação em Comunicação Audiovisual [entre crianças de 9 e 12 anos]

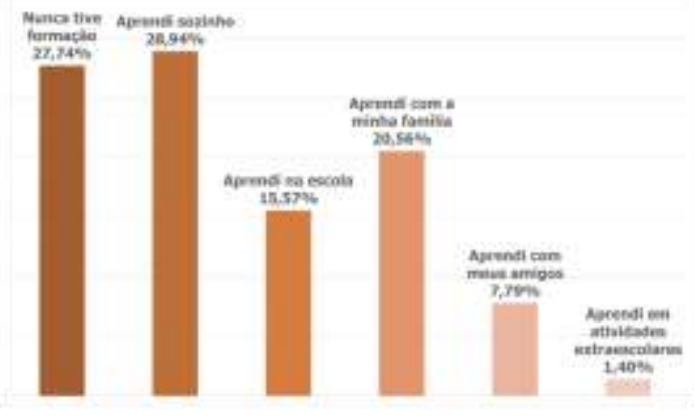

Fonte: SILVA;CARNEIRO;MEYER(2019, p.43)

Chama atenção que a principal forma de aprendizagem tenha sido a autodidata/aprender sozinho, seguido de uma diferença de um ponto percentual com nunca ter tido formação. Nessa faixa etária, a família aparece em terceiro lugar e a escola em quarto, com uma diferença de cinco pontos percentuais. O papel dos amigos nesse segmento parece ocupar pouco destaque, o que nos leva a questionar o lugar da aprendizagem colaborativa na especificidade da questão.

A escola demonstra ter pouco protagonismo na aprendizagem destas crianças com as mídias, o que indica um espaço a ser ocupado pela formação escolar no sentido da ampliação de suas competências midiáticas. "De modo geral, os participantes demonstraram ter um nível bastante básico de competência midiática em cada dimensão, sendo orientados muito mais pela intuição do que por um conhecimento mais sistematizado"( SILVA;CARNEIRO;MEYER, 2019, p.51).

No perfil dos jovens estudantes entre 14 e 16 anos participantes da pesquisa, 53,31\% são do gênero feminino e $46,69 \%$ masculino, provenientes dos estados de MG $(24,25 \%)$, SC $(20,64 \%)$, PR $(20,04 \%)$, SP $(8,81 \%)$ e DF (26\%). Os perfis socioculturais de cada contexto da pesquisa variam muito, e revelam uma diversidade de origens de classe, condições sociais, etnias, procedências geográficas e capital cultural que dificulta certas generalizações. As dimensões de acesso aos artefatos mostram que 96,99\% possuem televisão, 93,59\% smartphone e 80,76\% computador/notebook. (FANTIN;BORGES, 2019). 
Na pergunta sobre a formação recebida, evidenciamos: Nenhuma formação $(21,84 \%)$ e Alguma formação (78,16\%), sendo estas assim detalhadas: pouca $(30,06 \%)$, suficiente $(35,67 \%)$, bastante $(12,42 \%)$, o que demonstra uma diferença notável em relação ao outro segmento etário.

Na pergunta sobre como os estudantes entre 14 e 16 anos adquiriram formação audiovisual : 39,28\% aprenderam sozinhos (autodidatas), 18,44\% com ajuda de colegas, $18,24 \%$ com ajuda de familiares, $7,01 \%$ com ajuda de professores e 1,40\% em workshops. E 15,63\% não receberam formação, como podemos ver no gráfico a seguir:

Gráfico 2. Como os participantes [estudantes entre 14 e 16 anos] adquiriram formação audiovisual

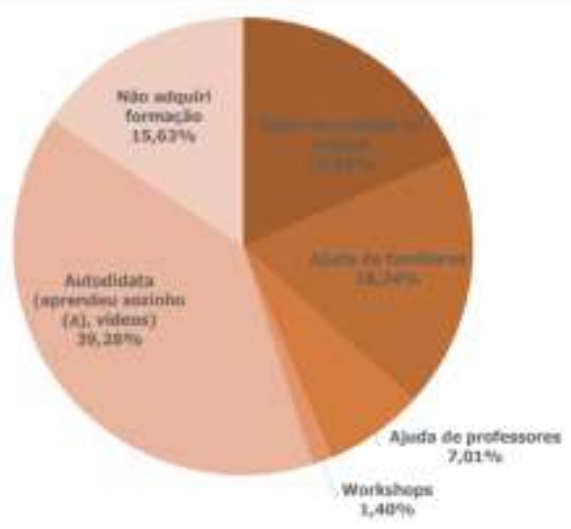

Fonte: FANTIN;BORGES, 2019, p.67.

Tais respostas nos levam a pensar na importância que a aprendizagem autodidata assume entre os jovens estudantes, ocupando primeiro lugar, seguido de um quase "empate técnico" da aprendizagem com os pares, que ficou em segundo lugar, e a ajuda de familiares em terceiro. Parece que o grupo de pares assume lugar destaque sobretudo pelas aprendizagens colaborativas que ocorrem no espaço escolar e fora dele, conforme o sentido de autoaprendizagem descrito por Sefton-Green (2019) e os indicadores de autodidaxia propostos por Belloni (2010). Mas o que mais chama nossa atenção nessas respostas foi o lugar da escola e/ou dos professores e sua pouca importância, ou quase ausência, para esses estudantes entre 14 e 16 anos participantes da pesquisa.

Se o "aprender sozinho" e/ou com a mediação dos pares assumem maior importância nessa faixa etária a partir do grupo de afinididades sugerido por Gee (2006), não deixa de ser interessante que a mediação familiar apareça ainda antes da mediação escolar na construção de tais competências. Isso pode indicar tanto algumas variáveis ligadas ao capital cultural familiar que possibilita tal mediação, como a baixa presença de educação midiática na escola, e a pouca 
articulação entre as aprendizagens formais e informais, referendando outras constatações de pesquisas a esse respeito (BONILLA;PRETTO 2015, FANTIN, 2016).

Resguardadas as devidas especificidades etárias, ao aproximarmos os dados da formação e a construção das competências audiovisuais entre crianças e jovens estudantes, veremos que a presença da mediação escolar reduz a quase $50 \%$ com o desenvolvimento da escolaridade.

Gráfico 3. Formação e aprendizagens sobre comunicação audiovisual

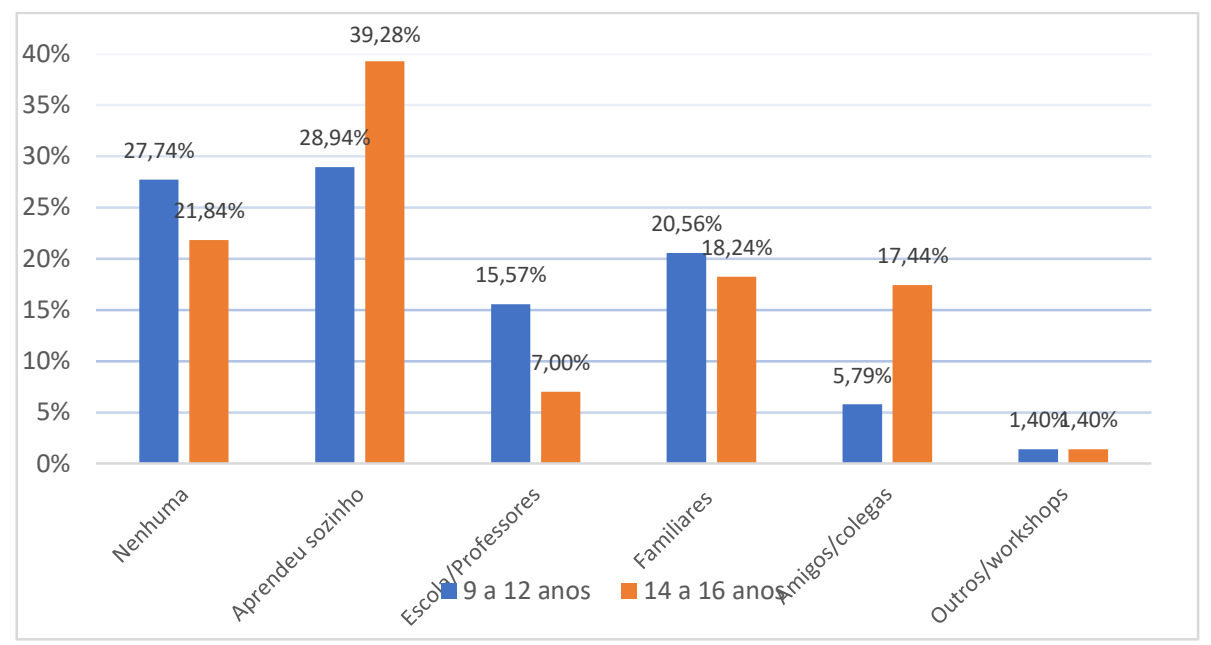

Fonte: Elaborado pela autora

Ainda que o aprender sozinho seja a forma mais evidente nos processos formativos relacionados às competências audiovisuais em ambas faixas etárias, seguido de nenhuma formação, além da quase ausência da escola em tal percurso, tais dados nos levam a refletir sobre o papel do outro na formação, em que a presença de amigos, família ou escola modifica seus lugares e suas "referências" nos diferentes momentos da vida, conforme Livingstone (2017) elucida sobre as mediações capacitadoras e/ou restritivas.

Enquanto a família aparece em terceiro lugar em ambas faixas etárias, o papel da escola/professores e amigos/colegas e seus lugares na formação se alternam. Entre 9 e 12 anos a escola/professores aparece em quarto lugar (15,57\%) e os amigos em quinto lugar, (5,79\%). Já entre os jovens estudantes de 14 e 16 anos, os amigos aparecem em quarto lugar $(17,44 \%)$ perto dos familiares, e a escola em quinto lugar $(7,0 \%)$. Tal mudança pode ser compreensível se considerarmos a importância do grupo e das aprendizagens colaborativas, pois suas práticas midiáticas e competências já são mais reconhecidas em diversos espaços sociais, inclusive na escola quando alguns estudantes são convidados a "ajudar" o professor como monitores no uso de certos artefatos. 
A inquietante "quase ausência" da escola na formação parece legitimar certas intuições que o senso comum revela sobre tal lacuna e ou defasagens que nos levam a perguntar: Se a escola está se eximindo de tal mediação, como potencializar e/ou assegurar um olhar crítico sobre as práticas midiáticas estudantis? Como questionar as buscas, as fontes de informação, a confiabilidade do que acessam, produzem e compartilham seus estudantes? Como refletir sobre tais práticas no espaço escolar se estão quase ausentes dessa formação? E ainda, será que a escola e seus profissionais têm noção ou consciência de que estão abdicando desse importante papel da mediação educativa crítica e responsável? E o que dizem as políticas públicas, os currículos e a formação docente a esse respeito?

É comum ouvirmos que certos meios digitais são considerados "auto-alfabetizantes", e que crianças e jovens aprendem a usar as tecnologias sozinhos, por descoberta, ensaio e erro. Mas se isso ocorre com a dimensão técnica instrumental, o mesmo não ocorre com a reflexão crítica que necessita da mediação do outro, da pergunta, da desestabilização de certas hipóteses e certezas que levam os estudantes a pensar sobre suas práticas culturais e midiáticas, sobre o que leem, acessam, consomem, produzem, compartilham, etc. .

Assim, uma análise mais geral pode evidenciar ainda mais a importância das mediações na formação e nas práticas crítico-reflexivas com as mídias, referendando os princípios da mídia-educação (RIVOLTELLA, 2005, FANTIN, 2011). E para assegurar experiências e práticas midiáticas entre crianças e jovens na perspectiva de uma cidadania de pertencimento instrumental e cultural, enfatizamos a necessidade de que os programas curriculares e as políticas públicas educacionais avancem no sentido de contemplar uma abordagem culturalista e ecológica da mídia-educação, que implica trabalhar pedagogicamente com todos os meios e tecnologias disponíveis, de forma a articular as perspectivas crítica-reflexiva, metodológicainstrumental e produtiva- expressiva da mídia-educação.

Diversos autores tem questionado o discurso dos "nativos e imigrantes digitais" a partir de uma discussão crítica a esse respeito (SELWYN, 2009, RIVOLTELLA, 2018, FANTIN 2016). E se os jovens estudantes estão criando significados diversos a partir de seus modos de participação na cultural digital e produzindo seus próprios meios, nem sempre revelam capacidades reflexivas e críticas sobre tais práticas e produções, afirma Buckingham (2010, p.294). Por isso a importância de articular aprendizagens formais e informais nas propostas formativas, tenha-se consciência delas ou não.

Nessa perspectiva, além do mapeamento das competências midiáticas, a referida pesquisa desenvolveu diversas propostas formativas sobre o tema para crianças, jovens, e professores, como se pode ver em Borges e Silva (2019). 


\section{OS DESAFIOS DA FORMAÇÃO E DA MEDIAÇÃO NA EDUCAÇÃO MIDIÁTICA}

Ao longo do texto discutimos a importância das multiliteracias e das diversas formas de entender a aprendizagem no contemporâneo, bem como o papel da formação nas competências midiáticas entre crianças e jovens estudantes de diferentes cenários socioculturais no contexto de uma pesquisa interinstitucional. Situamos aspectos da aprendizagem autodidata e evidenciamos sua presença no percurso de aprendizagem entre os estudantes participantes da pesquisa. Também refletimos sobre o sentido e as diferentes possibilidades de mediação educativa na cultura digital, em que evidenciamos a quase ausência da escola na aprendizagem midiática e na construção das competências audiovisuais. Por fim interrogamos alguns modos de assegurar a construção e/ou consolidação das competências midiáticas por meio da formação mediadora, o que requer estudos e práticas contínuas e qualificadas.

Alguns desafios colocados pela formação entendida como mediação referendam o que diversos estudos sinalizam, e reforçam o argumento da importância da inclusão curricular da educação para as mídias e multiliteracias, pois a mídia-educação é hoje uma condição de cidadania. Ainda que sejam crescentes as experiências formativas no âmbito das competências midiáticas nos mais diferentes contextos, uma atuação de forma qualificada na cultura digital ainda deixa a desejar. E ainda que a diversidade de documentos oficiais, as propostas curriculares, as práticas culturais em associações e os movimentos sociais tenham inspirado outras possibilidades para a educação midiática na escola e fora dela, os desafios ainda são enormes. Sobretudo se considerarmos as questões que hoje se colocam a partir das Fake News, da educação online, do controle de dados, da inteligência artificial, os desafios da formação assumem outro sentido.

Uma formação que articule os saberes formais e informais de estudantes e professores de modo a construir outros diálogos e práticas, implica necessariamente dialogar com o território, com as famílias e outros espaços sociais. Uma formação entendida como mediação que capacite, que instigue o pensar, que provoque reflexões sobre o que se sabe o que ainda precisa saber transcende o uso das mídias e tecnologias. Afinal, quem trabalha com formação sabe que este processo é muito mais complexo, pois se os usos das tecnologias que asseguram práticas e desenvolvimentos das competências não forem sustentados por uma consciência metodológica, é provável que as aprendizagens desencadeadas não ocorram na perspectiva esperada ou até mesmo que nem se evidenciem aprendizagens, pois a relação entre digital e escola/formação não é determinista, é uma relação complexa e sistêmica. E tal entendimento significa considerar ambientes, dispositivos e artefatos num sistema de relações que envolvem também os consumos e as práticas midiáticas de estudantes e professores.

Uma formação atenta às múltiplas linguagens que crianças e jovens utilizam considera também suas multimodalidades, que estão cada vez mais presentes na construção de sentidos e nas interações com as 
telas. E se é papel da escola/formação favorecer experiências culturais na perspectiva da construção da cidadania e assegurar mediações educando crianças e jovens às linguagens midiáticas e plurais que transcendem a palavras e a escrita, há que considerar também as linguagens do corpo, da música, das imagens, da materialidade e textura das diversas culturas.

Formar e/ou educar para os usos destas linguagens significa também interrogar sobre o problema de como ensinar crianças e jovens a ler, produzir e refletir usando todos os meios assegurando as diversas dimensões neste universo: a dimensão semiótica (a produção de mensagens e os conhecimentos sobre o funcionamento das linguagens, suas gramáticas e sintaxes); a dimensão expressiva/estética (além de conhecer as linguagens saber utilizar de modo criativo e produzir conteúdos estéticos e significativos); e a dimensão ética (considerar os limites da representação e do que pode ser publicado e/ou compartilhado, o que requer responsabilidade de quem produz e compartilha).

Enfim, ao pensar o lugar da formação nesse contexto em que as mídias/tecnologias nos atravessam, nosso desafio de professores/pesquisadores é construir mediações de modo que os estudantes possam atravessá-los também, com consciência, criatividade e responsabilidade. É com essa compreensão mais ampla desse processo mídia-educativo que afirmamos a importância da mediação construída nos mais diferentes espaços da educação formal e informal, sobretudo no papel da escola e dos professores neste processo de ensinar e aprender que envolve a constante negociação, criação e transformação de significados na cultura.

\section{REFERÊNCIAS}

AGUADED, I. La competencia mediática, una acción educativa inaplazable. (Editorial). Comunicar n.39, p.7-8. 2012.

BELLONI, Maria L. Crianças e mídias no Brasil. Campinas: Papirus, 2010.

BOCHICCHIO, Franco. Autoformazione. In QUALIGNO, G. P. (a cura di). Formazione: i metodi. Milano: Raffaello Cortina, 2014, p.49-68.

BONILLA, Maria H.; PRETTO, Nelson. Política educativa e cultura digital: entre práticas escolares e práticas sociais. Perspectiva, v36, n.2, p.499-521, maio/ago,2015.

BORGES, Gabriela; SILVA, Marcia B. (orgs). Competências midiáticas em cenários brasileiros: interfaces entre comunicação educação e artes. Juiz de Fora: Editora da UFJF, 2019.

BUCKINGHAM, David. Do we really need media education 2.0. In DROTNER, K. SCHRØDER, K.C. (Eds.). Digital content creation: perceptions, practices and perspectives. New York: Peter Lang, 2010, p.289-304. 
COPE, B.; KALANTZIS, M. (Eds). Multiliteracies: literacy learning and the design of social futures. New York: Routledge, 2000.

CRESWELL, J. W. Projeto de Pesquisa: métodos qualitativo, quantitativo e misto. 3 a d. Porto Alegre: Artmed, 2010.

DIODATO, Roberto. Sobre o sentido da experiência estética. Revista Tempos e Espaços da Educação. V.8, n.17, Set/Dez, $2015 . \quad$ Disponível em: https://seer.ufs.br/index.php/revtee/article/view/4511 Acesso em: 19 set 2020.

DOZOL, Marlene. Da figura do mestre. Campinas: Autores Associados: São Paulo: EDUSP, 2003.

FANTIN, Monica. Mídia-educação: aspectos históricos e teórico-metodológicos. Olhar de Professor, v.13, .p27-40, 2011.Disponível em: https://www.revistas2.uepg.br/index.php/olhardeprofessor/article/view/3483/2501 Acesso em 21 abr. 2020.

FANTIN, Monica. Nativos e imigrantes digitais em questão: crianças e competências midiáticas na escola. Passagens. v.7, n.1, p. 5-26, 2016. Disponível em: http://www.periodicos.ufc.br/ passagens/article/download/3652/3279. Acesso em: 23 set. 2019.

FANTIN, Monica. Conhecimento estético, tecnologias da sensibilidade e experiências formativas de crianças, jovens e professores. Revista Tempos e Espaços em Educação.V11, n.26, jul-set, 2018. Disponível em: https://seer.ufs.br/index.php/revtee/article/view/8834 Acesso em: 19 set. 2020.

FANTIN, Monica; BORGES, Gabriela. Competências midiáticas e a produção audiovisual entre jovens: experiências investigativas e formativas. In BORGES, G.; SILVA, M. B. (orgs). Competências midiáticas em cenários brasileiros: interfaces entre comunicação educação e artes. Juiz de Fora: Editora da UFJF, 2019, p.57-83.

FERRÉS, Joan. La competência en comunicación audiovisual. Comunicar, n. 29, p. 100-107, 2007. Disponível em: https://www.revistacomunicar.com/verpdf. php?numero=29\&articulo=29-2007-17. Acesso em: 23 ago. 2014.

FERRÉS, Joan; PISCITELLI, Alejandro. La competencia mediática: propuesta articulada de dimensiones e indicadores. Comunicar, n. 38, p.75-82, 2012. Disponível em: https:// www.revistacomunicar.com/verpdf.php?numero=38\&articulo=38-2012-10. Acesso em: 23 ago. 2014.

GARCÍA-RUIZ, Rosa, GOZÁLVEZ-PÉREZ, Vincent, \& AGUADED GÓMEZ, Ignacio La competencia mediática como reto para la educomunicación: instrumentos de evaluación. Cuadernos.Info, (35), 15-27, 2014.

GEE, James P. What Video Games Have to Teach Us About Learning and Literacy. London: Palgrave Macmillan, 2006.

ITO, Misuko; BAUMER, Sonja; BITTANTI, Matteo; BOYD, Danah; CODY, Rachel; HERR-STEPHENSON, Becky. ET AL. Hanging Out, Messing Around, and Geeking Out: Kids Living and Learning with New Media. Boston Mass: The MIT Press, 2010. 
LIVINGSTONE, Sonia. Digital skills matter in the quest for the 'holy grail'. In: Pareting for a Digital Future. Fev 2017.2 Disponivel em: https://blogs.Ise.ac.uk/parenting4digitalfuture/2017/02/07/digital-skills-matter-in-the-quest-forthe-holy-grail/ Acesso em: 21 jun. 2019.

MARTIN-BARBERO, Jesus. Dos meios às mediações: comunicação, cultura e hegemonia. 2. Ed. Rio de Janeiro: Editora da UFRJ, 2001.

OROZCO, Guillermo. Meios, audiências e mediações. Comunicar, n.8, p.25-30, 1997.

ORTIZ, Renato. O caminho das mediações. In MELLO, J. M.; DIAS, P. R. (orgs). Comunicação, cultura, mediações: o percurso intelectual de Jesus Martin-Barbero. São Paulo: Unesp, 1999.

QUALIGNO, Gian P. (ed). Formazione: i metodi. Milano: Raffaello Cortina, 2014.

RIVOLTELLA, Pier C. Formar a competência midiática: novas formas de consumo e perspectivas educativas. Comunicar, n. 25. p.1-6 2005. Disponível em: https://www. redalyc.org/articulo.oa?id=15825168. Acesso em: 23 abr. 2015.

RIVOLTELLA, Pier C. Un'ideia di scuola. Brescia: Morcelliana, 2018.

SEFTON-GREEN, Julian. Towards a cultural history of digital autodidactism: changing cultural narratives of education. Perspectiva, v.37, n.1, p.125-139, jan/mar, 2019.

SELWYN, Neil. The digital native-myth and reality. Aslib Proceedings, 61(4), 364-379, 2009.

SILVA, Márcia B.; CARNEIRO, Vania L. Q.; MEYER, Mariana. Crianças de 9 a 12 anos e sua relação com a mídia. In BORGES, G.; SILVA, M.B. (orgs). Competências midiáticas em cenários brasileiros: interfaces entre comunicação educação e artes. Juiz de Fora:Editora da UFJF, 2019, p.36-56.

SILVERSTONE, Roger. Por que estudar a mídia. São Paulo: Loyola, 2005.

TISSERON, Serge. 3-6-9-12 Diventare grande all'epoca degli schermi digitali. Brescia:La Scuola, 2016.

UNESCO. Alfabetização midiática e informacional: currículo para formação de professores. Brasília: UNESCO/UFTM, 2013.

\section{SOBRE A AUTORA:}

\section{Monica Fantin}

Doutora em Educação (UFSC), Professora Associada da Universidade Federal de Santa Catarina; Programa de Pós-Graduação em Educação da UFSC; Líder do Grupo de Pesquisa Núcleo Infância, Comunicação, Cultura e Arte.

E-mail: monica.fantin@ufsc.br

ORCID: https://orcid.org/0000-0001-7627-2115

Recebido em: 02/07/2020

Aprovado em: 22/09/2020

Publicado em: 07/10/2020 